\title{
How life cycle-based science and practice support the transition towards a sustainable economy
}

\author{
Matthias Stucki ${ }^{1}$ (D) Marleen Jattke ${ }^{1} \cdot$ Marcus Berr $^{2} \cdot$ Harald Desing $^{2} \cdot$ Ashley Green $^{3,4} \cdot$ Stefanie Hellweg $^{5}$. \\ Rafael Laurenti ${ }^{6} \cdot$ Ronny Meglin $^{7} \cdot$ Karen Muir $^{1} \cdot$ Dario Pedolin $^{3,8} \cdot$ Rhythima Shinde $^{5} \cdot$ Tobias Welz $^{9}$. \\ Regula Lisa Keller ${ }^{1}$
}

Received: 4 March 2021 / Accepted: 18 March 2021 / Published online: 12 April 2021

(c) The Author(s) 2021, corrected publication 2021

Keyword LCA · sustainable economy $\cdot$ transition $\cdot$ decision-making $\cdot$ policy $\cdot$ circular economy

\section{Introduction}

Politicians, activists, and researchers are striving towards a more sustainable economy. A comprehensive way to analyse the environmental sustainability of systems are methods based on life cycle assessment (LCA). At the 74th Discussion Forum on Life Cycle Assessment (DF LCA) held on June 29, 2020, the role of different life cycle-based approaches for generating scientific knowledge about a sustainable economy were discussed within the LCA community. These life cycle-based approaches were applied and further developed within the various research projects of the Swiss National Research Programme "Sustainable Economy: resource-friendly, future-oriented, innovative" (NRP 73). This programme includes 29 research projects and generates scientific knowledge for the transition towards a sustainable economy, discovers untapped resource efficiency potential and contributes to achieving the Sustainable Development Goals of the United Nations (Betz et al. 2020).

At the LCA Discussion Forum, twelve researchers presented their methodological LCA approaches within their NRP73 projects. Sixty participants from academia, con-

Communicated by Matthias Finkbeiner.

Matthias Stucki

stucki@zhaw.ch

1 Institute of Natural Resource Sciences, Zurich University of Applied Sciences (ZHAW), Wädenswil, Switzerland

2 Technology and Society Lab, Empa - Swiss Federal Laboratories for Material Science and Technology, St. Gallen, Switzerland

3 Agroscope, Research Group Life-Cycle Assessment, Zürich, Switzerland

4 Department of Health Sciences and Technology, Institute of Food, Nutrition and Health, ETH Zürich, Zürich, Switzerland sultancy, industry, and public authorities engaged in the interactive conference. Bastien Girod, President of the Commission for Environment, Energy and Spatial Planning of the Swiss National Council, opened the day with a keynote on the role of LCA and rebound effects for a net zero carbon economy. The forum consisted of four thematic sessions that covered the topics of the different research projects where life cycle-based approaches were used. These topics were circular and sharing economy (1), public and private consumption (2), food production and consumption (3), and sustainable cities (4). For each topic, the methods presented were evaluated based on how they could contribute to a sustainable economy by addressing three overarching issues:

1. How can decision-makers use life cycle-based approaches to boost sustainable decisions?

2. Which life cycle-based approaches are best suited to reveal opportunities and risks for sustainability within the different economic sectors?

3. Which instruments are most useful for combining environmental, economic, and societal aims?

These issues were additionally discussed in bilateral sessions, where experts exchanged their knowledge in

5 Department of Civil, Environmental and Geomatic Engineering, ETH Zürich, Institute of Environmental Engineering, Zürich, Switzerland

6 Department of Machine Design, KTH Royal Institute of Technology, Stockholm, Sweden

7 University of Applied Sciences of Eastern Switzerland, Rapperswil, Switzerland

8 Department of Environmental Systems Science, Institute of Agricultural Sciences, ETH Zürich, Zürich, Switzerland

9 Research Centre for Digital Sustainability, University of Berne, Berne, Switzerland 
discussion groups of two and shared their insights using an online tool. These insights are presented in the last chapter.

\section{Circular and sharing economy}

The circular economy vision has raised awareness for the need to move from a linear economy to one where the value of materials and products is kept in the system as long as possible. The UNEP/SETAC life cycle initiative argues that LCA is suited as a tool to understand the environmental and social implications of circular economy strategies, as well as identifying the most promising of those strategies (Pena et al. 2020). Circularity in connection with sustainability can be addressed from different angles. In this forum, resource efficiency as a design principle was discussed as well as a method to systematically evaluate the environmental benefits of recycling and the quantification of sustainability benefits from sharing platforms.

Resources are crucial for a sustainable economy since resource extraction, processing, and final disposal are responsible for a large share of the anthropogenic burdens on the environment (Oberle et al. 2019). To reach environmental sustainability in a circular economy, resource inputs thus need to be restricted to what can be safely extracted, processed, and released back into the environment (Desing et al. 2020, 2021). An optimal design of services and products within an economy can reduce the pressure on resources and lead the way to a circular economy. Harald Desing (Empa) presented the resource pressure method (Desing et al. 2021). It precedes an LCA and provides practical means to support decision making during the design phase. It comprises qualitative design guidelines such as the recommendation to reduce product mass and increase lifetime or recyclability of products. In addition, Desing's approach includes a single score indicator for the quantification of the effectiveness of circular design strategies. This allows the evaluation of circular design alternatives and their prioritization. To calculate the resource budget, life cycle data, and expertise is necessary, but practitioners in the industry only need to handle six parameters in the resource pressure method. This simplification facilitates the use of the method throughout the design process by product designers or engineers and can thus be a crucial part in developing designs for a sustainable economy. Data from the resource pressure method can later be used to expand to a more detailed ex post LCA.

While recycling is often considered to automatically lead to an environmental benefit, the actual benefit depends on the impact of the raw material, the recycling process, and the value retention (VR) after the process. Existing performance indicators of a circular economy fail to capture the sustainability dimension of various VR processes. Stefanie Hellweg (ETH Zurich) described a new indicator which quantifies the
Retained Environmental Value (REV) (Haupt and Hellweg 2019). This indicator is the ratio of the net environmental benefits of the VR process divided by the original production impacts. Hence, a value of $100 \%$ means that the full environmental value is retained without any losses (e.g. in a direct reuse scenario). A value between 0 and $100 \%$ means that part of the value is retained (with the difference to $100 \%$ quantifying the losses). A negative REV indicator indicates that the VR process produces more impacts than it is able to save, and hence, this VR process should not be carried out. The indicator can be quantified in terms of any environmental impact category, and expansion to include the economic and social dimensions is planned for the future research. Example of circular solutions for glass, newsprint, and motor blocks illustrated the use of the REV indicator.

In addition to sustainable design and circular solutions, a large sustainability potential lies in business models that contribute to a sharing economy. Rafael Laurenti (KTH Royal) presented the NRP 73 project 'RE:Share Rebound Effects of the Sharing Economy' which aims at evaluating the motivations of users and the environmental benefits of consumer-to-consumer product sharing platforms In Switzerland and Sweden. He analysed the activities of 6600 people who shared products such as log splitters, utility trailers, and garden tillers, as well as data from almost six times as many people who were benefiting from these possibilities. The greenhouse gas (GHG) emissions saved due to the sharing platform were calculated based on the carbon footprint per monetary unit using 12 household consumption categories provided in the EXIOBASE 3 database (Stadler et al. 2018). In addition to substitution effects, Laurenti considered rebound effects due to the respending of marginal earnings in order to estimating the net environmental savings from sharing. He emphasized the importance of the aggregated effects of consumption of different products, behavioural changes, and a system perspective in order to adequately estimate the environmental benefits of businesses in a sharing economy.

\section{Responsible public and private consumption}

The second session focused on life cycle-based approaches in the context of responsible public and private consumption. SDG 12 of the United Nations (2015) 2030 agenda for sustainable development emphasized the need for practices to reduce the footprint of global consumption. Hence, the session covered presentations on sustainability indicators for sustainable value chains and sustainability monitoring of public consumption, as well as business models that promote sustainable private consumption. 
Marcus Berr (Empa) presented the project "Open Assessment of Swiss Economy and Society" (OASES) that aims at assessing the environmental, economic, and social impacts of Swiss production and consumption. Within this project, Empa's objective is to evaluate physical, geopolitical, economic, and regulatory supply risks along the complete supply chain by identifying and applying pertinent indicators within the life cycle sustainability assessment (LCSA) framework. These supply risk indicators were identified by collecting existing supply disruption probability and vulnerability indicators from literature and by evaluating their suitability regarding an integration into the LCSA framework. As could be shown, the database ecoinvent, EXIOBASE, and the Social Hotspot Database (SHDB) do not currently allow sufficient quantification of identified indicators such as "fragility in legal systems" of governances and "economic value of imports" from trade partners. As a next step, Empa will therefore investigate possibilities of complementing these databases with data from additionally identified data sources. Two options would be to consider the governance information of the Worldwide Governance Indicators provided in the World Bank and to complement trade data from the UN Comtrade database.

Tobias Welz (University of Berne) presented how the sustainability performance in public procurement can be monitored through life cycle thinking. He showed that in order to boost sustainable decision-making in public procurement (UNEP 2017), it is crucial to identify the sustainability challenges throughout all product categories and to monitor the sustainability performance of public agencies (Bolz et al. 2018).

Public agencies use the concept of Common Procurement Vocabulary (CPV) (European Commission 2008) to comprise all kinds of goods and services to describe the subjects of contracts. It is therefore essential to incorporate sustainability issues to this given concept using qualitative and quantitative life cycle management methods (Jensen and Rehnert 2006). First, it is key to derive ecological and social hotspots using sustainable hotspot analysis (Faist Emmenegger and Schlierenzauer 2019) along the supply chain on sector level (qualitative approach). Second, these hotspots must be converted into quantitative approaches like the concept of the Most Economically Advantageous Tender (MEAT) (European Commission 2015) or life cycle costing (LCC) (Estevan et al. 2017), to be accounted for in public procurement activities. Both steps reveal to which extent sustainability criteria are included in public tenders. This allows monitoring of the penetration of sustainability and the applied level of sustainability over time in public agencies on federal, cantonal, and municipal level.

Applying the above mentioned approach for Swiss public procurement conditions, an in-depth-analysis on ICT hardware procurement was performed (Welz and Stuermer 2020).
The findings of this study offer the opportunity to report progress of national sustainable development through public procurement, using the MONET framework (Altwegg et al. 2004). As governments spent $12 \%$ global GDP to purchase goods and services from the private sector (World Bank 2020), and in Europe even more than 14\% GDP (European Commission 2016), comprehensive sustainable decisionmaking in public procurement can leapfrog to the urgently needed contributions towards local, regional, national, and international sustainability goals (United Nations Economic and Social Council 2019).

Marleen Jattke (ZHAW) showed how business models can extend the lifetime of mobile internet-enabled devices and therefore contribute to more sustainable consumption (Jobin et al. 2020; Jattke et al. 2020). As discussed during the 73rd Discussion Forum on Life Cycle Assessment on global digital transformation, an increasing number of mobile Internet-enabled devices (MIEDs), whose production requires large amount of resources, energy, and causes emissions during production, are being sold (Itten et al. 2020). Extending the lifetime of MIEDs can significantly reduce their ecological footprint. Therefore, the target of the "LifeSaving" research project is to develop innovative business models to stimulate the lifetime extension of mobile devices. Recent LCA studies show that the production of integrated circuits (ICs) accounts for the majority of GHG emissions during the production phase. However, there is only little information available on MIED specific components such as logic or memory type integrated circuits. In order to quantify environmental impacts of lifetime extension of MIEDs, new approaches for life cycle inventory modelling (e.g. modular modelling) are being developed within the "LifeSaving" project.

Lifetime extending measures are subject to rebound effects, which occur if the number of devices being produced does not fall as expected or consumption in other sectors increases. Such effects depend on consumer behaviour and the rationalities of economic actors involved. Thus, environmental, behavioural, and economic aspects have to be taken into account in order to develop lifetime extending business models that entail environmental benefits while being both economically viable and appealing to consumers.

\section{Food production and consumption}

Due to its high sustainability impact, food production and consumption is an area that received particular interest in the research on the sustainability transformation of the economy. The sustainable development goals SDG 2 zero hunger, SDG 3 good health and well-being, SDG 6 clean water, SDG 13 climate action, SDG 14 life below water, and SDG 15 life 
on land are directly affected by global food production and consumption (United Nations 2015).

Dario Pedolin (Agroscope) applied data envelopment analysis in order to aggregate life cycle impacts for eco-efficiency assessment. With the aim of guiding economic development into a sustainable future, methodologies that integrate economic and environmental aspects are needed. The eco-efficiency framework (Huppes and Ishikawa 2005) allows for the joint assessment of measures of economic performance and environmental impacts. One difficulty when using eco-efficiencies is the need to aggregate multiple environmental impacts (and multiple outputs), each with its own units and order of magnitude. Data Envelopment Analysis as suggested by Kuosmanen $\&$ Kortelainen (2005) can be used to aggregate these different environmental impact categories, without having to specify a set of weightings. Instead, the available data on comparable actors is used to estimate a best practice frontier from which the individual eco-efficiency scores can be calculated. The combination of LCA and DEA allows decision-makers to jointly consider economic and environmental issues and can reveal opportunities for improvements and risk (cost of avoided environmental burden). Finally, the LCA and DEA tool chain can be used to combine economic, environmental, and social aspects for efficiency assessments (Vásquez-Ibarra et al. 2020).

Ashley Green (Agroscope, ETH Zurich) held a talk on the transformation of the food sector by integrating nutrition into LCA (Green et al. 2020). Nutritional Life Cycle Assessment (n-LCA) is a nascent but needed method to quantitatively assess the sustainability of our food sector. N-LCA seeks to account for the multi-functionality of food, and it incorporates measures of health, nutritional adequacy, diversity, and quality into environmental LCA. By doing this, it jointly accounts for the nutritional, health, and environmental sustainability dimensions of agri-food production systems and sustainable diets. Identifying best practices in n-LCA (e.g., normalization, points of differentiations amongst nutrition metrics), therefore, will allow actors in the production and consumption sectors to identify trade-offs and synergies amongst sustainability dimensions and to translate these findings into alleviating global sustainability challenges such as climate change, biodiversity loss, micronutrient deficiencies, and dietary disease.

\section{Sustainable cities}

More than half the world's population lives in cities, which is why cities play a decisive role in sustainability transformation. With SDG 11 in the United Nations 2030 Agenda, sustainable cities and communities are a prominent goal (United Nations 2015). The session on sustainable cities focused on the regional building material industry, sustainable housing, and a sustainable healthcare sector.
Ronny Meglin (University of Applied Sciences of Eastern Switzerland) presented the environmental and economic assessment of a regional building material industry by combining material-flow-analysis, input-output-analysis, and life cycle assessment. In the building material industry, sustainability concerns are dominated by the role of raw materials, especially in the production of cement and concrete. As locally sourced materials can have significant environmental impacts, the industry deals with conflicting goals between economy and environment. Driven by this challenge, public pressure, and stricter regulations, companies are starting to extend their business models with additional services to start a transition towards a sustainable construction industry (Meglin et al. 2019). To quantify these processes and their ecological impacts, an integrated assessment model needs to be developed.

Meglin presented an assessment model for environmental and economic impacts in form of environmentally and monetary extended input-output-tables (IOT) based on material flow analysis (MFA) and life cycle assessment (LCA). This assessment will create the possibility to indicate the impacts of changing material flows or innovations on the life cycle most relevant for generating value added, causing emissions and consuming natural resources on a regional level. The results highlight the impact of a specific business model and show how this affects environmental and economic performance of a regional building materials industry. On this basis, policy recommendations can then be derived which promote the development of a circular economy in the building materials industry in a regional context.

Rhythima Shinde (ETH Zurich) demonstrated her research on sustainable housing and life cycle tools that support understanding residents' consumption and their rebounds. Environmental policies that lead to a reduction in the price of a product or service, e.g. rents, may result in increased consumption of the housing-related products or consumers may buy other products, e.g. more flights, leading to a substantially different magnitude of environmental impacts than initially expected. Shinde's study aims to calculate this difference, using a random forest method, by investigating rebound impacts of housing-related policies that are caused due to the savings of households due to the price (e.g. rent) changes, in Switzerland. These effects vary by income group and household size (e.g., higher income groups have higher travel rebounds and associated increase in emissions).

It can be seen from the results that sustainable measures taken by building owners or cooperatives might have worseoff effects, if the induce saving of rent (e.g. energy savings, smaller houses). This explorative data mining study allows incorporating effects of all the household properties (and consumption behaviours), and thus help overlap the economic aspect of the consumptions, consequence of an affordable 
housing policy and its final environmental impact. In addition, this study allows the consideration of effects of any consumption industry on another, allowing assessing the risks and opportunities of savings-induced rebounds (spill overs).

Karen Muir (ZHAW) presented how green best-practice can be developed for hospitals using an LCA approach. The "Green Hospital" project is a multidisciplinary project of LCA Research Group at the Zurich University of Applied Sciences together with partners from the Fraunhofer IML and the Institute for Economic Studies in Basel. They are analysing hospitals from environmental, economic, and logistical perspectives. The environmental hotspots of Swiss hospitals were determined to be catering, building infrastructure, housekeeping supplies, and energy provision (Keller et al. 2021). The high variability in impact per full time equivalent implies a large potential for environmental optimisation.

Decision-makers can use life cycle-based approaches to boost sustainable decisions by setting priorities based on concrete hotspots and using LCA-benchmarking to determine areas of potential improvement. The life cycle-based approaches best suited to reveal opportunities and risks for sustainability are multi-stage analyses, combinations of bottom-up analyses with extrapolation, LCA case studies, and key parameter models. In order to combine environmental, economic, and societal aims, instruments from different disciplines should be used in order to show the economic and social benefits of environmental optimisation.

\section{Discussions and conclusions}

At the 74th Discussion Forum on Life Cycle Assessment (LCA), twelve researchers shared their experiences on how decision-makers can use life cycle-based approaches to boost sustainable decisions, which life cycle-based approaches are best suited to reveal opportunities and risks for sustainability within different economic sectors, and which instruments are most useful for combining environmental, economic and societal aims.

In an interactive session, the 60 participants from academia, consultancy, industry, and public authorities exchanged their experiences on how life cycle-based approaches can support the transition towards a sustainable economy. The results show that complexity, data availability, lack of priority, and cost were identified as major obstacles for mainstreaming life cycle thinking in the economy (see Fig. 1). In order to support life cycle thinking by various stakeholders in the economy, life cycle-based decision support needs to be transparent and easily understandable. Simplifying tools and approaches to model complex systems, as well as providing a wide range of data sources have the potential to overcome obstacles for mainstreaming life cycle thinking in our economy. Decision makers in economy need to be made aware that they can make an important contribution to more life cycle thinking by setting priorities and making resources and data available.

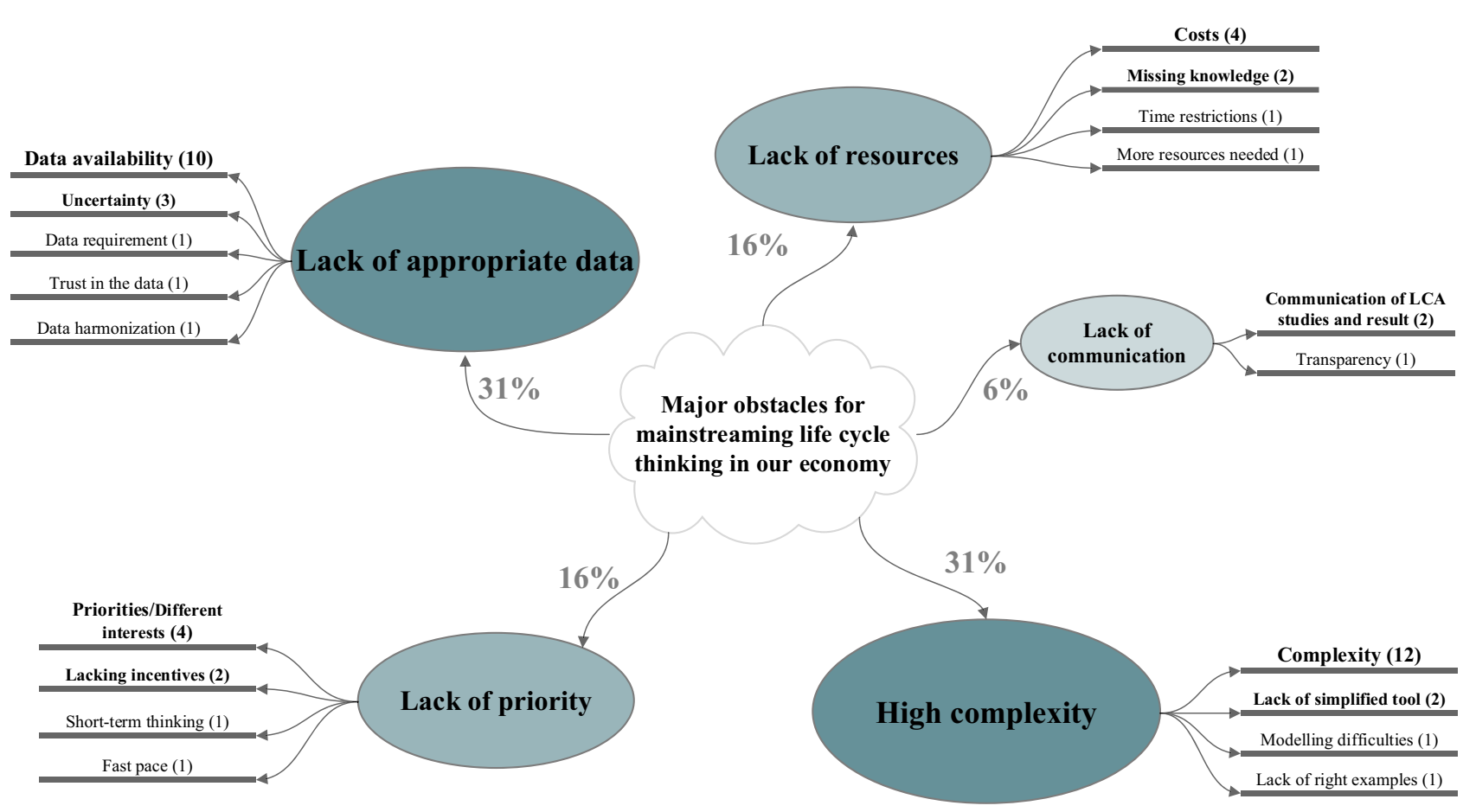

Fig. 1 Participants' perspective on major obstacles for mainstreaming life cycle thinking in the economy (the number of mentions is indicated in parentheses; a total of 51 responses were submitted by participants) 
As Bastien Girod emphasized in his keynote speech, embodied emissions and LCA are becoming increasingly relevant, and products will increasingly include information about their footprint. It is expected that policies will take embodied emissions and LCA more and more into account. Brand-specific LCA can be an incentive for change within supply chains.

Analysis of sustainability hotspots was considered to be particularly helpful to support decision-makers in making more sustainable decisions (see Fig. 2). For example, sustainability hotspots based on LCA were used for the identification of best practises in the context of the "Green Hospital" project presented by Karen Muir. Additionally, Tobias Welz presented how a hotspot analysis can be used to derive environmental and social hotspots along the supply chain at sector level and then translate them into quantitative approaches for monitoring sustainability performance in public procurement.

In addition to analysing sustainability hotspots, ecodesign and circular economy were perceived as most useful in helping decision makers to choose more sustainable options. For example, new practical indicators developed within the NRP73, such as the retained environmental value (REV) presented by Haupt and Hellweg (2019) or the resource pressure indicator presented by Desing et al. (2020, 2021) can support decision makers during the design phase to reach environmental sustainability in a circular economy. Furthermore, life cycle-based approaches related to communication, benchmarking, and simplification were considered by the participants as key for decision-making that supports the Sustainable Development Goals of the 2030 Agenda.

With regard to the question which instruments the participants have used to combine environmental, economic, and societal sustainability aspects, they responded diversely with a broad range from monetization or system models, over combined labelling, or transparent reporting up to economy for the common good, or life cycle sustainability assessment (LCSA). The range of different answers to this question revealed that there is not yet a consensus on how to integrate environmental, economic, and societal sustainability among the LCA community that reflects practical experience.

One approach to integrate different sustainability dimensions applied within the NRP73 is the combination of the eco-efficiency framework with data envelopment analysis as presented by Dario Pedolin in the session dedicated to

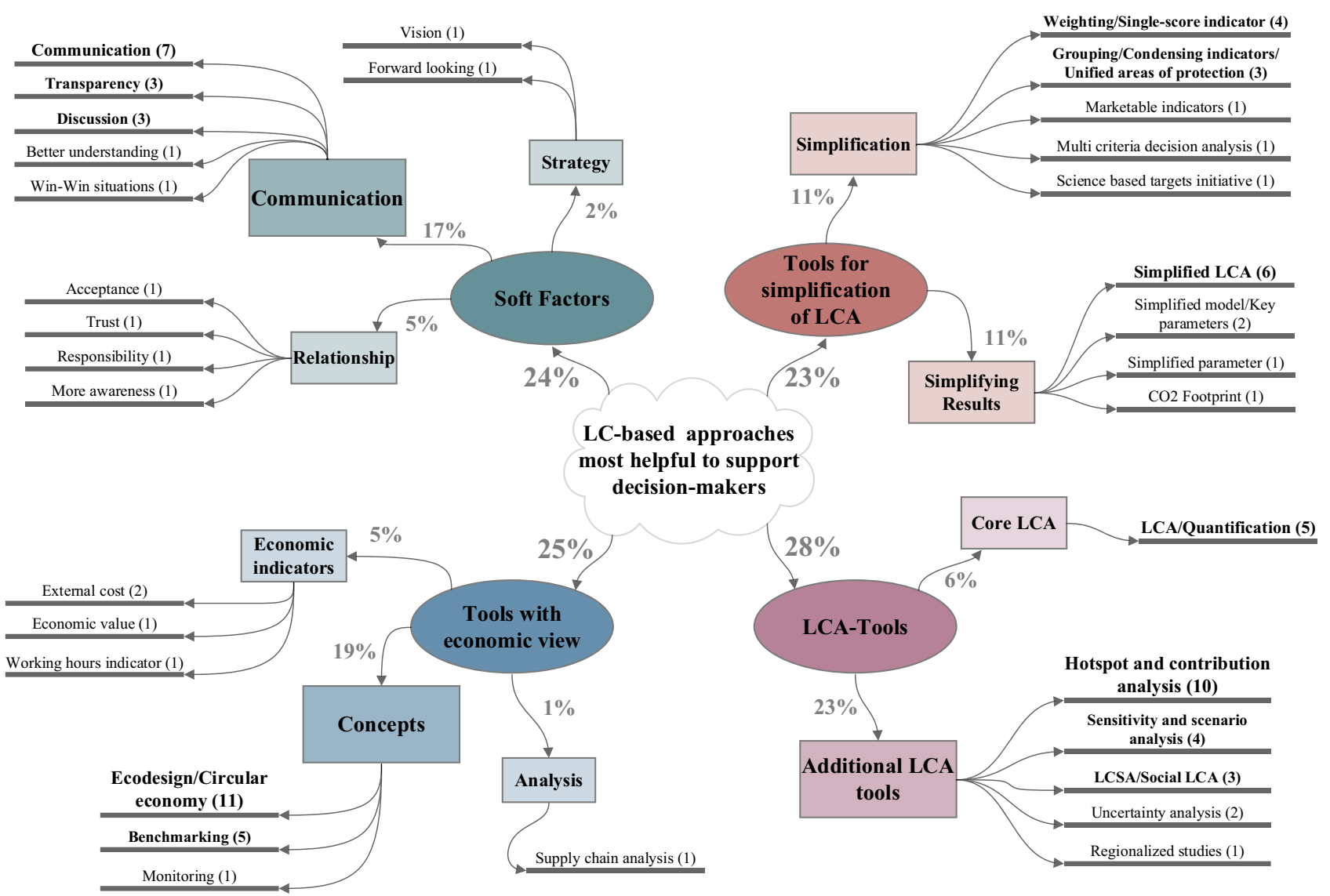

Fig. 2 Participants' view on which life cycle-based approached proved to most helpful to support decision-makers in making more sustainable decisions (the number of mentions is indicated in parentheses; a total of 88 responses were submitted by participants) 
food production and consumption. Ashley Green showed an approach how to integrate nutritional, health, and environmental sustainability dimensions in the context of food. Marleen Jattke presented how to select economically viable business models which have environmental benefits and are socially accepted to incentivize more sustainable consumption. To monitor sustainability performance in public procurement, Tobias Welz chose an approach to integrate environmental and social hotspots along supply chains.

Regarding life cycle-based approaches that best reveal risks and opportunities of products and services, the conference participants reported hotspot analysis, sensitivity, and scenario analysis, as well as the critical discussion of the results.

The 74th Discussion Forum on Life Cycle Assessment (LCA) revealed the important role of life cycle assessment and other life cycle-based approaches in guiding and monitoring transformation towards a sustainable economy.

Acknowledgements The 74th Discussion Forum on Life Cycle Assessment was organized by the Research Group Life Cycle Assessment at the Zurich University of Applied Sciences (ZHAW).

Funding The 74th LCA Discussion Forum and this publication are based on research supported by the Swiss National Science Foundation (SNSF) within the framework of the National Research Programme "Sustainable Economy: resource-friendly, future-oriented, innovative" (NRP 73) Grant No. 407340_172453.

Open Access This article is licensed under a Creative Commons Attribution 4.0 International License, which permits use, sharing, adaptation, distribution and reproduction in any medium or format, as long as you give appropriate credit to the original author(s) and the source, provide a link to the Creative Commons licence, and indicate if changes were made. The images or other third party material in this article are included in the article's Creative Commons licence, unless indicated otherwise in a credit line to the material. If material is not included in the article's Creative Commons licence and your intended use is not permitted by statutory regulation or exceeds the permitted use, you will need to obtain permission directly from the copyright holder. To view a copy of this licence, visit http://creativecommons.org/licenses/by/4.0/.

\section{References}

Altwegg D, Roth I, Scheller A (2004) Monitoring sustainable development - MONET. Swiss Federal Statistical Office (SFSO), Neuchâtel

Betz R, Gunter S, Anderson A, et al (2020) Overview of the State of Research in NRP 73: a well-designed political framework and consumption and production patterns for a sustainable economy. Swiss National Science Foundation (SNSF)

Bolz U, Lüthi P, Eicher B, Müller P (2018) Corporate social responsibility (CSR) Der Bund als Beschaffer. Federal Office for Spatial Development, Berne / Zurich

Desing H, Braun G, Hischier R (2021) Resource pressure-a circular design method. Resour Conserv Recycl 164:105179. https://doi. org/10.1016/j.resconrec.2020.105179
Desing H, Brunner D, Takacs F et al (2020) A circular economy within the planetary boundaries: towards a resource-based, systemic approach. Resour Conserv Recycl 155:104673. https://doi.org/ 10.1016/j.resconrec.2019.104673

Estevan H, Schaefer B, Adell A (2017) Life cycle costing state of the art report. Local Governments for Sustainability, European Secretariat

European Commission (2008) Regulation No 213/2008 of the European Parliament and of the Council on the Common Procurement Vocabulary (CPV) and Directives 2004/17/EC and 2004/18/EC of the European Parliament and of the Council on public procurement procedures, as regards the revision of the $\mathrm{CPV}$

Commission E (2015) Public procurement-guidance for practitioners on the avoidance of the most common errors in projects funded by the European Structural and Investment Funds. Publications Office of the European Union, Luxembourg

Commission E (2016) Buying green! A handbook on green public procurement, 3rd edn. Publications Office of the European Union, Luxemburg

Faist Emmenegger M, Schlierenzauer C (2019) Relevanzmatrix - Orientierungshilfe für Beschaffende und Bedarfsstellen Methodenbericht zu den ökologischen und sozialen Kriterien. Federal Office for the Environment FOEN

Green A, Nemecek T, Chaudhary A, Mathys A (2020) Assessing nutritional, health, and environmental sustainability dimensions of agri-food production. Glob Food Sec 26:100406. https://doi. org/10.1016/j.gfs.2020.100406

Haupt M, Hellweg S (2019) Measuring the environmental sustainability of a circular economy. Environmental and Sustainability Indicators 1-2:100005. https://doi.org/10.1016/j.indic.2019.100005

Huppes G, Ishikawa M (2005) Eco-efficiency and Its xsTerminology. J Ind Ecol 9:43-46. https://doi.org/10.1162/108819805775247891

Itten R, Hischier R, Andrae ASG et al (2020) Digital transformationlife cycle assessment of digital services, multifunctional devices and cloud computing. Int J Life Cycle Assess 25:2093-2098. https://doi.org/10.1007/s11367-020-01801-0

Jattke M, Bieser JCT, Blumer Y et al (2020) Environmental implications of service life extension of mobile devices. WEEE plastic characterization and recyclability assessment: a case study for household appliances. Fraunhoferverlag, Stuttgart, pp 163-170

Jensen AA, Rehnert A (2006) Background Report for a UNEP Guide to Life Cycle Management: A Bridge to Sustainable Products

Jobin M, Külling C, Jattke M, Blumer YB (2020) Extending the lifetime of mobile devices to reduce their environmental impact: a glimpse on the project Lifesaving. SocietyByte

Keller RL, Muir K, Roth F, Jattke M, Stucki M (2021) From bandages to buildings: identifying the environmental hotspots of hospitals. Manuscript submitted for publication

Kuosmanen T, Kortelainen M (2005) Measuring eco-efficiency of production with data envelopment analysis. J Ind Ecol 9:59-72. https://doi.org/10.1162/108819805775247846

Meglin R, Kliem D, Scheidegger A, Kytzia S (2019) Business-models of gravel, cement and concrete producers in Switzerland and their relevance for resource management and economic development on regional a scale. IOP Conference Series: Earth and Environmental Science 323:012170. https://doi.org/10.1088/1755-1315/ 323/1/012170

Oberle B, Bringezu S, Hatfield-Dodds S et al (2019) Global resources outlook: 2019. International Resource Panel, United Nations Envio

Pena C, Civit B, Gallego Schmid A, et al (2020) Using life cycle assessment to achieve a circular economy. Life Cycle Initiative

Stadler K, Wood R, Bulavskaya T et al (2018) EXIOBASE 3: Developing a time series of detailed environmentally extended multiregional input-output tables. J Ind Ecol 22:502-515 
UNEP (2017) global review of sustainable public procurement 2017. United Nations Environment Programme

United Nations (2015) Transforming our world: the 2030 agenda for sustainable development

United Nations Economic and Social Council (2019) Special Edition: progress towards the Sustainable Development Goals-report of the Secretary-General

Vásquez-Ibarra L, Rebolledo-Leiva R, Angulo-Meza L et al (2020) The joint use of life cycle assessment and data envelopment analysis methodologies for eco-efficiency assessment: a critical review, taxonomy and future research. Sci Total Environ 738:139538. https://doi.org/10.1016/j.scitotenv.2020.139538
Welz T, Stuermer M (2020) Sustainability of ICT hardware procurement in Switzerland - a status-quo analysis of the public procurement sector. [cs]. https://doi.org/10.1145/3401335.3401352

World Bank (2020) How large is public procurement? https://blogs. worldbank.org/developmenttalk/how-large-public-procurement. Accessed 27 Jul 2020

Publisher's Note Springer Nature remains neutral with regard to jurisdictional claims in published maps and institutional affiliations. 